
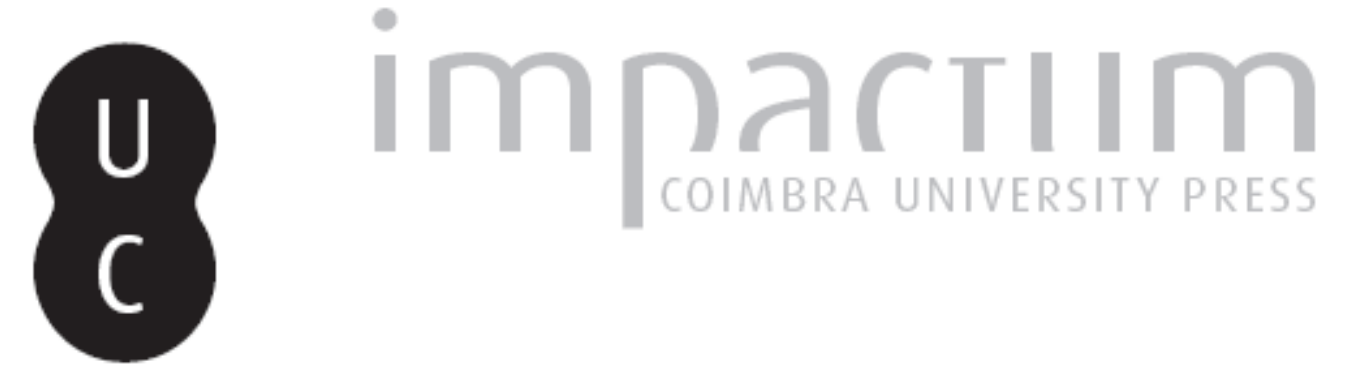

\title{
Elenchos, intelectualismo y verguënza en el Gorgias de Platón
}

\section{Autor(es): Bieda, Esteban}

Publicado por: Annablume Clássica; Imprensa da Universidade de Coimbra

URL persistente:

URI:http://hdl.handle.net/10316.2/36129

DOI:

DOI:http://dx.doi.org/10.14195/1984-249X_14_7

Accessed : $\quad$ 26-Apr-2023 07:46:26

A navegação consulta e descarregamento dos títulos inseridos nas Bibliotecas Digitais UC Digitalis, UC Pombalina e UC Impactum, pressupõem a aceitação plena e sem reservas dos Termos e Condições de Uso destas Bibliotecas Digitais, disponíveis em https://digitalis.uc.pt/pt-pt/termos.

Conforme exposto nos referidos Termos e Condições de Uso, o descarregamento de títulos de acesso restrito requer uma licença válida de autorização devendo o utilizador aceder ao(s) documento(s) a partir de um endereço de IP da instituição detentora da supramencionada licença.

Ao utilizador é apenas permitido o descarregamento para uso pessoal, pelo que o emprego do(s) título(s) descarregado(s) para outro fim, designadamente comercial, carece de autorização do respetivo autor ou editor da obra.

Na medida em que todas as obras da UC Digitalis se encontram protegidas pelo Código do Direito de Autor e Direitos Conexos e demais legislação aplicável, toda a cópia, parcial ou total, deste documento, nos casos em que é legalmente admitida, deverá conter ou fazer-se acompanhar por este aviso.

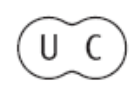




\section{4}

jan/jun

2015

issn 2179-4960 e-issn 1984-249-X
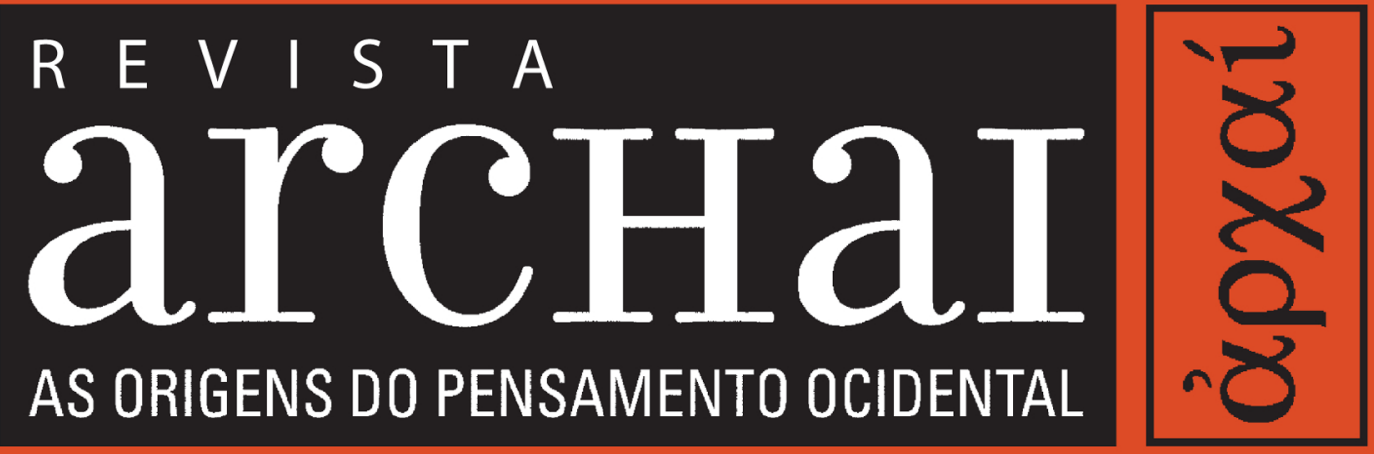

ARCHAI JOURNAL: ON THE ORIGINS OF WESTERN THOUGHT

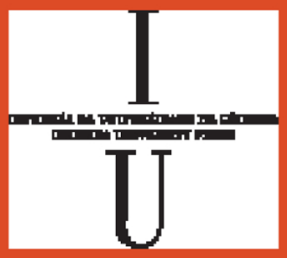

\section{archaI}

AS ORIGENS Do PENSAMENTO OCIDENTAL 


\title{
ELENCHOS, INTELECTUALISMO Y VERGÜENZA EN EL GORGIAS DE PLATÓN
}

\author{
Elenchos, Intellectualism and Shame in Platós Gorgias
}

BIEDA, E. (2014). Elenchos, intelectualismo y vergüenza en el Gorgias de Platón. Archai, n. 14, jan - jun, p. 77-91

DOI: http://dx.doi.org/10.14195/1984-249X_14_7

RESUMEN: En el presente trabajo nos proponemos destacar un aspecto del elenchos socrático que denominaremos "abordaje práctico", marco en el que intentaremos resaltar el compromiso situacional y emocional de la refutación socrática que, tal como se halla bien atestiguado en el Gorgias de Platón, supone el contexto de una conversación efectiva entre dos interlocutores frente a terceros. A su vez, este abordaje se revelará "práctico" también en la medida en que, según intentaremos mostrar, guarda una relación estrecha con el "Intelectualismo socrático" (IS) en lo que a las posibilidades prácticas del interlocutor al momento de ser interrogado respecta. Veremos cómo en el Gorgias, si bien se da el caso de una acción realizada en contra de lo que el agente tiene por verdadero, dicha situación no constituye un contraejemplo del IS, pues lo que se pone en juego al momento de tomar decisiones éticamente relevantes no se agota en el nivel proposicional de las opiniones acerca de la situación práctica concreta, sino que puede involucrar, como en el caso de Gorgias y Polo, la vergüenza que significaría responder, ante una audiencia que se asume con opiniones contrarias, lo que realmente se piensa. Así, buscamos concluir que la teoría socrática de la acción se haya íntimamente relacionada con el elenchos por cuanto éste último abarca, no sólo el repertorio de proposiciones epistémicas de los agentes involucrados, sino también sus estados existenciales en relación con la mirada de terceros al momento de sostener públicamente una posición teórica determinada y éticamente relevante.
* Universidad de Buenos Aires - CONICET (estebanbieda@gmail.com)

1. Quizás la más 'neutral' o 'general' sea la definición de Robinson: "en un sentido amplio, 'elenchos' significa examinar a una persona en relación con una afirmación que ha hecho, mediante un interrogatorio que da lugar a ulteriores afirmaciones, con

la esperanza de que tales afirmaciones determinarán el significado y valor de verdad

de su afirmación inicial" (1996, p. 9, nuestra trad.).

2. Cf. Vlastos (1994: caps. I y II).

3. Cf. Benson (1987) y (1995). Más allá de estas dos posiciones generales, puede verse un resumen representativo de las líneas interpretativas más importantes del elenchos en Prior (1996).

\section{Esteban Bieda}

“En seguida un sentimiento de vergüenza se apoderó de él y le hizo cambiar el modo de pensar"

Tolstoi, Ana Karenina

“No quieren las mismas cosas que dicen, sino que dicen las palabras más decorosas, pero quieren las cosas que parecen provechosas".

Aristóteles, Refutaciones sofisticas 172b36-39

La cuestión de la refutación o interrogatorio socrático (elenchos) ha sido largamente debatida durante las últimas décadas dando lugar a un gran número de interpretaciones ${ }^{1}$. Entre las más reputadas, puede nombrarse la ya clásica corriente representada por G. Vlastos, según la cual el elenchos es un método que se utiliza para probar la falsedad de las creencias del interlocutor y, en consecuencia, la verdad de las afirmaciones de Sócrates ${ }^{2}$. Como alternativa a esta línea exegética, interpretaciones como la de Benson han intentado mostrar que el elenchos no puede probar ni la verdad ni la falsedad de las proposiciones comprendidas en un argumento, sino que se limita a detectar la eventual inconsistencia entre ellas: Sócrates no estaría denunciando la falsedad de las afirmaciones de sus interlocutores, sino su incoherencia lógica ${ }^{3}$. Ambas clases de interpretaciones pueden agruparse en lo que 
PALABRAS CLAVES: Elenchos; Intelectualismo socrático; Sócrates; Platón; Gorgias

ABSTRACT: In this paper I intend to underline an aspect of the socratic elenchos that we call "practical approach". Within this framework I emphasize the relationship between Socratic refutation and the situation and emotions involved in it, as it is well testified in Plato's Gorgias, where the conversation takes place in public. Our approach also reveals itself as being "practical" since it has, as I try to show, a very close link to the so called "Socratic Intellectualism" (SI). In the Gorgias, even if a case in which a decision contrary to what the agent considers better for himself is made can be found, this situation does not constitute a counterexample for the SI, insofar as what is important at the moment of making decisions is not just the opinions the agent has at a propositional level, but also the shame that could be involved in case some specific answer is given in front of an audience. Thus, our conclusion is that the Socratic theory of action is closely related to the elenchos since the latter involves not only the epistemic opinions of the agent but also his existencial condition linked to the presence of other people.

KEYWORDS: Elenchos; Socratic intellectualism; Socrates; Plato; Gorgias

podríamos denominar "abordajes epistemológicos" del elenchos, por cuanto se centran, sobre todo, en sus aspectos metodológicos en referencia a los contenidos proposicionales de las discusiones. De allí que se comprometan con conceptos como los de "verdad", "falsedad" o "consistencia"

Hay, con todo, un tercer grupo de interpretaciones según las cuales en el Gorgias Sócrates apela, en su refutación a Gorgias y a Polo, a factores irracionales como la vergüenza antes que al razonamiento. Dicha vergüenza chocaría con ciertas convicciones morales profundas e intuitivas que, a la postre, llevarían a refutar la posición del agente en cuestión ${ }^{5}$. No obstante, propuestas como esta - que cargan las tintas en los condimentos irracionales presentes en la refutación - no prestan especial atención a dos elementos que, en nuestra propia interpretación del diálogo, serán centrales: la presencia de terceros y el rol del así llamado "intelectualismo socrático" (IS) en lo que a la conservación práctica del agente respecta.

Así, en una línea de argumentación que, en cierto modo, podría enrolarse con esta última, en el presente trabajo nos proponemos destacar un aspecto del elenchos que, desde ya, no excluye los abordajes epistemológicos ${ }^{6}$. Nos referimos a lo que denominaremos "abordaje práctico" ${ }^{7}$, marco en el que intentaremos resaltar el compromiso situacional y emocional de la refutación socrática que, tal como se halla bien atestiguado en el Gorgias de Platón, supone el contexto de una conversación efectiva entre dos interlocutores, por lo general frente a terceros. El hecho de que quienes discuten lo estén haciendo en persona, cara a cara, sumado al hecho de que tales discusiones tengan lugar, en la mayor parte de los casos, en público, aporta una serie de elementos que, a nuestro entender, sirven para enriquecer el significado y función filosófica del elenchos. A su vez, este abordaje también se revelará "práctico" en la medida en que, según intentaremos mostrar, guarda una relación estrecha con el IS en lo que a las posibilidades prácticas del interlocutor al momento de ser interrogado respecta. Veremos cómo en el Gorgias, si bien se da el caso de una acción realizada en contra de lo que el agente tiene por verdadero, dicha situación no constituye un contraejemplo del IS. Según veremos, lo que se pone en juego al momento de tomar decisiones éticamente relevantes no se agota en el nivel proposicional de las opiniones acerca de la situación práctica concreta, sino que puede involucrar, como en el caso de Gorgias y Polo, la vergüenza que significaría responder, ante una audiencia que se asume con opiniones contrarias, lo que realmente se piensa. Así, buscamos concluir que la teoría socrática de la acción se haya íntimamente relacionada con el elenchos por cuanto éste último abarca, no sólo el repertorio de proposiciones epistémicas de los agentes involucrados, sino también sus estados existenciales en relación con la mirada de terceros al momento de sostener públicamente una posición teórica determinada y éticamente relevante.

\section{Los términos "elenchos", "elenchein", "elencheie" y "elenches"}

El sustantivo "elenchos" - directamente relacionado con el verbo "elenchein"- puede ser rastreado hasta Homero. Sin embargo, el significado en los poemas épicos es en principio distinto al que
4. Este abordaje también ha sido denominado "lógico"; cf. v.g. Renaud (2001: nota 62).

5. Cf. Moss (2005). Futter (2009) critica la posición de Mosspero destacando, fundamentalmente, la capacidad razonadora de la vergüenza y el placer ("shamejudgements" y "pleasurejudgements", respectivamente)

6. Ya Kahn ha mostrado que el elenchos tiene este "doble carácter": "como examen de la verdad y coherencia tanto de las proposiciones que sostiene el interlocutor como de su propia vida" (1996, p. 60, nuestra trad.)

7. Otros antes que nosotros han hecho un abordaje de esta índole, fundamentalmente Kahn (1996) y Brickhouse-Smith (1996). Estos últimos han mostrado, específicamente, cómo el elenchos no tiene como única meta la refutación de las proposiciones del interlocutor, sino tamibién dar cuenta de cómo hay que vivir la vida y otra serie de metas existenciales. Cf. también Inverso (2013) y Cosentino (2013), entre otros. 
encontramos en los diálogos de Platón. En efecto, en Homero el sustantivo suele traducirse "vergüenza" y el verbo, en consecuencia, "avergonzar" o "poner en vergüenza" ${ }^{\prime \prime}$. Siguiendo a 0sthoff, Chantraine vincula

8. Cf. Chantraine s.v. "honte" y LSJ s.v. "reproach", "disgrace",

“dishonour". El término tiene este mismo sentido no sólo en Homero, sino también en Hesíodo (cf. v.g.Th. 26) y en Píndaro (cf. v.g.N. 3.15). Cabe señalar que el sustantivo homérico es de género neutro y el ático es masculino, lo cual, no obstante, no parece incidir especialmente en el significado, dado que el neutro plural también se aplica a personas: cf. v.g. Il. 2.235

9. Chantraine, s.v. "elencho"; nuestra trad

10. Las traducciones de los textos griegos son nuestras.

11. Para otras apariciones de "elenchos" y "elenchein" en Homero, cf. v.g.Ilíada2. 285;4 242; 5.787 (como apósito de aidos); 8 . 228;9.314; 22. 100; Odisea $10.72 ; 21.329$ y 333 el verbo elencho con el adjetivo elachys ("pequeño", "corto"), a partir de lo cual concluye que "el sentido originario sería, entonces, 'disminuir' (amoindrir), 'rebajar' (rebaisser), sentidos que convienen tanto a los usos homéricos como a los jurídicos y dialécticos del jonio y el ático" ${ }^{\prime 9}$. Como se ve, este 'rebajar a otro', 'disminuir a otro' tendría, según Chantraine, connotaciones tanto morales como dialécticas: un "elenchos" sería tanto una puesta en vergüenza como una refutación.

Yendo por un momento a los usos épicos, las connotaciones minimizadoras son claras. Humillado por el autoritarismo de Agamenón, Tersites exhorta al ejército aqueo, también humillado y sometido por el rey micénico, al punto de haber quedado casi en el lugar de una mujer: "blandas, funestas vergüenzas (elenchea), aqueas, que ya no aqueos" (Il. 2. 235) ${ }^{10}$. La pérdida de la masculinidad por parte de quienes se definen sobre todo por su hombría es la peor bajeza que se puede perpetrar. Esta vergüenza vinculada con la pérdida del propio status se repite cuando Agamenón afirma que no tomar Troya significaría volver a Argos "lleno de vergüenza (elenchistos)" (Il. 4. 171). El soldado que partió a Troya, el soldado cuya razón de ser era tomar la ciudad de Príamo, ni muere en combate ni toma la ciudad, sino que vuelve a su tierra derrotado. La pérdida de esa razón de ser, equivalente a la pérdida de la masculinidad del ejército en la cita anterior, es considerada un "elenchos" superlativo. Una pérdida similar de la masculinidad padece Eurímaco, pretendiente de Penélope, cuando afirma que no haber podido torcer el arco dará lugar a una vergüenza (elencheie) que durará por años (Od. 21. 255).

La interpretación que proponemos vincula esta vergüenza con la pérdida de la compostura, no sólo moral, sino también existencial: el soldado que no puede cumplir con su esencia guerrera es vergonzoso, pues se vuelve un hombre carente de hombría. En las antípodas de esta pérdida de la compostura, el hecho de ser quien se es, es lo contrario a la vergüenza. Odiseo ya ha derrotado a los pretendientes acertando los blancos y torciendo el arco; todavía disfrazado, le habla a Telémaco: “el huésped que albergas no genera vergüenza (elenchei) en tus salas: no erré ningún blanco y torcer este arco no me dio gran quehacer" (Od. 21. 424). No hay vergüenza en la sala porque, aun cuando esté disfrazada, la persona que realizó tales proezas es la persona cuya razón de ser consistía en realizarlas. Se ve, pues, que el parámetro de la vergüenza se relaciona específicamente con el rol esencial de cada uno: vergonzoso para Odiseo hubiese sido no acertar los blancos, mientras que vergonzoso para el porquerizo es que sus perros muerdan a un desconocido (Od. 24. 38). Lo "vergonzoso" parece relacionarse, pues, con lo que cada uno es o debería ser: no hubiese sido vergonzoso para Odiseo que Argos mordiera a un extraño, del mismo modo que no hubiese sido vergonzoso para el porquerizo no torcer el arco o acertar los blancos: ninguna de esas dos cosas les corresponde ${ }^{11}$.

Destaquemos, entonces, que el tipo de vergüenza al que hacen referencia los usos épicos relevados tiene que ver con cierta pérdida del status propio del agente involucrado, con cierta "disminución", como sugería Chantraine, de aquello que supuestamente es o debería ser. Se trata, en definitiva, de cierta clase de 'contradicción' o 'tensión' entre lo que determinado hombre es y el lugar en que lo ponen las circunstancias. Este mismo sentido tiene el término en su única aparición en Hesíodo. Las Musas interpelan a los pastores: "pastores de los campos, funestas vergüenzas (elenchea), como vientres <que tan sólo son>" (Teogonía 26). Los pastores, hombres reducidos a sus vientres (gasteres), minimizados en su humanidad, son considerados, por eso mismo, "vergüenzas funestas". De allí, también, el siguiente texto de Trabajos y días: "el hombre cobarde se procura un amigo diferente cada vez. Que el pensamiento no desmienta (katelencheto) en nada a tu rostro" (714). Mediante la forma compuesta "katelenchein", Hesíodo aboga por la integridad, por la unidad entre eidos y nous, entre aspecto visible y pensamiento, cuando de enfrentar a oportunistas y cobardes se trata: es ese, podríamos decir, un signo de altura, frente a la bajeza moral del cobarde. Ese “desmentir" (katelenchein) hace referencia, pues, a 
la detección y sanción de algo vergonzoso y bajo: la integridad moral supone unidad entre lo que se piensa y lo que se muestra, entre el nous y el eidos.

Retomando, entonces, las dos connotaciones generales del término "elenchos", la moral ("vergüenza") y la dialéctica ("refutación"), en lo que sigue propondremos que el uso socrático no se desentiende, en determinados contextos, de estos matices, sino que los integra.

\section{Elenchos y vergüenza en el Gorgias}

Antes de avanzar sobre el tópico específico de la vergüenza y su relación con el elenchos, digamos algo acerca del tipo de conversación que Sócrates está queriendo mantener con sus tres interlocutores en el Gorgias. Si bien dicho en plena discusión con Calicles, las siguientes palabras valen también, creemos, para las conversaciones previas:

Si acaso acordaras algún punto conmigo en las discusiones, eso ya quedará suficientemente examinado por mi y por ti, y ya no necesitará de otra examinación, pues tú no lo aceptarías ni por falta de sabiduría, ni por un exceso de vergüenza (aischynes periousiai), ni tampoco lo aceptarías por engañarme, pues eres mi amigo, como tú mismo dices. Por lo tanto, nuestro mutuo acuerdo ya alcanzará, realmente, la meta de la verdad (telos tês aletheias) (487e).

Calicles se ha declarado amigable (philikos, $485 \mathrm{e} 3$ ) con Sócrates, lo cual supone, a criterio de este último, la sana voluntad de avanzar con la discusión, no con ánimo erístico sino filosófico: el intercambio dialéctico entre amigos no tiene como meta el triunfo sobre la posición del otro, sino la verdad. Como el texto recién citado muestra, esta "verdad" encontrará su objetivo en los sucesivos "acuerdos" (homologiai) que logren los interlocutores $^{12}$. Haberse dicho amigo de Sócrates compromente a Calicles, entonces, con una actitud integral frente al interrogatorio: aun cuando sean dos personas, una que pregunta y otra que responde, avanzan juntos y sinceramente hacia la verdad. Esta "sinceridad" 0 "libertad de expresión" se denomina "parresia" y el propio Calicles ha hecho gala de responder de ese modo $^{13}$. La parresia debe plasmarse, sobre todo, en las respuestas del interrogado que no deben contradecir sus verdaderas convicciones. Es esta regla lo que el propio Calicles viola cuando, interrogado por la diferencia o similitud entre el placer y el bien, responde: "para que el razonamiento no se me vuelva inconsistente (anomologoumenos) - <cosa que ocurriría> si acaso respondise que son distintos -, afirmo que son lo mismo". A lo cual Sócrates replica: "destruyes los primeros argumentos, Calicles: ya no podrías investigar conmigo suficientemente la realidad (ta onta) si respondes en contra de lo que tú mismo opinas (para ta dokounta sautoi)" (495a). He aquí una regla básica del interrogatorio socrático: el interrogado no debe responder en contra de sus opiniones, sino que debe ser sincero: "si se quiere lograr el objetivo último del elenchos, es esencial que quien responde esté, él mismo, convencido, independientemente de que algún otro lo esté; en primer lugar, debe creer en sus propias afirmaciones" ${ }^{14}$. Sentadas estas bases mínimas - que retomaremos más adelante - de las pretensiones y condiciones de la dialéctica en lo que a la actitud de los interlocutores respecta, avancemos sobre el tópico de la vergüenza.

\section{a) Gorgias}

Si bien tradicionalmente asociada con el comportamiento práctico, la vergüenza (aischyne ) ocupa un rol central en las sucesivas refutaciones que tienen lugar en el Gorgias ${ }^{15}$. Una particularidad de este diálogo es que la conversación no sólo es pública, sino que el auditorio anónimo es mencionado más de una vez a lo largo del diálogo, cosa que le otorga un rol fundamental en el desarrollo de los argumentos. Promediando la discusión con Gorgias (457a ss.), justo después de que el sofista afirmara que enseña la retórica para un uso justo y no para hacer con ella lo que se quiera, Sócrates le advierte sobre la posibilidad de que sea refutado si siguen conversando. Gorgias responde: “quizás sea necesario considerar <el parecer> de los presentes" (458b). Sin forzar la interpretación, puede pensarse que Gorgias intuye que Sócrates habrá de refutarlo, por lo que intenta evadirse apelando al eventual
12. La diferencia explícita entre erística y dialéctica, y su relación con la amistad de los interlocutores, es mencionada en Menón, a propósito de una eventual discusión entre dos hombres: "si quisieran dialogar entre ellos siendo amigos, como tú y yo ahora, es necesario que contesten más suave y dialécticamente (dialektikoteron). Quizás 'más dialécticamente' sea no sólo responder cosas verdaderas, sino también con aquellas cosas que el interrogado reconoce conocer" (75d). No hacer esto es dialogar erística o agonísticamente (eristicos, agonisticos).

13. Cf. Grg. 491e.

14. Robinson (1996, p.16; nuestra trad.). Cf. situaciones similares en R. 346e, La. $187 \mathrm{~d}$ y Prt. 336c.

15. Race (1979) rastrea 75 apariciones del término "aischyne" y sus cognados a lo largo del texto, a partir de lo cual afirma que la vergüenza es el leitmotiv del diálogo. 
aburrimiento del público. Una vez que Querefonte y Calicles confirman que el clamor (thorybos, 458c3) de los presentes da cuenta de que quieren continuar escuchando, Gorgias concluye: "por lo demás, es vergonzoso (aischron) que yo no quiera <responder>, habiendo requerido yo mismo que cualquiera preguntara lo que quisiera. Entonces, si les parece bien a estos aquí presentes (toutoisi), dialoga <conmigo> y pregunta lo que quieras" (458d-e). Dado que Gorgias se había presentado ante el auditorio como aquel que "exhortaba a que cualquiera de los que estábamos ahí preguntara lo que quisiera y decía que respondería a absolutamente todas las cosas" $(447 c)$, hubiese resultado vergonzoso abandonar la conversación con Sócrates. Nótese, pues, que la razón de esta vergüenza radica en la 'promesa' hecha a los presentes: Gorgias habría dejado de ser quien había dicho que era, habría quedado 'disminuido' ante el auditorio, en caso de no haber estado a la altura de su promesa. Pero no es esta la única vergüenza que aqueja al gran maestro de retórica.

El sofista afirma que el orador debe persuadir no de cualquier modo, sino con justicia (dikaios, 457b4), con vistas a una utilización justa (epi dikaiai chreiai, 457c1) de la palabra, por lo cual, en caso de que algún orador haga un uso injusto de la misma, no debe culparse a quien lo instruyó, sino al orador mismo. Luego de esto Sócrates le hace aceptar que quien conoce lo justo no puede sino obrar justamente y que, en caso de desconocer qué es lo justo, el propio Gorgias se lo enseñará (460ac). La contradicción resulta de haber afirmado que el orador puede utilizar su arte de manera injusta $y$, a la vez, que esto es imposible ${ }^{16}$. Es aquí cuando Polo toma la palabra:

¿Qué dices, Sócrates? ¿También tú opinas sobre la retórica así como dices? ¿0 crees - porque Gorgias sintió vergüenza (eischynthe) de no acordar contigo que el orador no conoce lo justo, lo bello y lo bueno y que, si acaso <alguno> acudiera hacia él no conociendo tales cosas, él mismo se las enseñaría, y luego, a causa, quizás, de este acuerdo, se siguió algo contradictorio (enantion ti) en la discusión - <o crees, decía > esto con lo que te deleitas, conduciendo tú mismo hacia tales interrogantes? Pues, ¿quién crees que niega que conoce lo justo y que se lo enseña a los demás? $(461 b-c)^{17}$

Desde el punto de vista de Polo, la mayoría de los hombres asume que conoce lo que está bien y que puede enseñarlo ${ }^{18}$. Negar esto frente a la multitud de oyentes hubiese sido, a criterio del propio Polo, vergonzoso para Gorgias, razón por la cual aceptó algo que en realidad no creía ${ }^{109}$. Esa concesión habría sido, a su vez, la causante de la contradicción y posterior refutación. Supongamos que Polo tiene razón y que Gorgias, retomando el espíritu del pasaje donde hacía referencia explícita al parecer de los oyentes (458b), dio más importancia a la mirada de tales oyentes que a la suya propia. Asumiendo esto - cosa que no resulta poco plausible desde el momento en que Gorgias no desmiente a Polo -, vemos que la vergüenza ha operado como factor más efectivo que la verdad (o, cuando menos, que la opinión que se tiene por verdadera): " $<$ la refutación de Gorgias> se sigue, no de sus creencias reales, sino de la afirmación de poder enseñar asuntos morales que se ve forzado a hacer debido a su posición en la esfera pública (public eye) ${ }^{\prime 20}$. Al hacer esto, Gorgias viola uno de los parámetros fundamentales del interrogatorio socrático que comentamos supra: la sinceridad y libertad en el decir (parresia). Más adelante en el diálogo, Calicles confirma este diagnóstico de Polo al afirmar que Gorgias "sintió vergüenza (aischynthenai) y dijo que sí le enseñaría <lo justo a un discípulo en caso de que no lo conocieras, e hizo esto a causa de la costumbre (ethos) de los hombres, porque se ofenderían si alguien dijera <que no puede enseñar lo justo>" (482d). La referencia explícita al éthos de los hombres a propósito de la enseñabilidad de asuntos vinculados con la justicia confirma que la vergüenza de Gorgias no se debió a las preguntas de Sócrates o a la contradicción en la que habría de quedar envuelto, sino a la mirada del auditorio y al lugar en el que quedaría parado frente a esa mirada ${ }^{21}$. De manera similar a la pérdida de masculinidad del ejército aqueo o de Eurímaco, incapaz de torcer el arco, Gorgias se enfrenta a una situación en la que su status se pone en juego: la credibilidad del sofista a propósito de sus capacidades educativas resulta equivalente a la hombría del soldado. Ha- 
berse asumido como alguien incapaz de enseñar lo justo y lo injusto habría significado la pérdida de su raison d'être en tanto comerciante de esa clase de conocimientos. Pero lo fundamental aquí es que esa disminución - que implicaría no poder afrontar el interrogatorio socrático, la vergüenza de tener que aceptar la incapacidad de seguir respondiendo - pesa más que la opinión teórica que Gorgias tiene respecto de lo que se discute. De allí que, en opinión de Polo, acepte algo en lo que no cree tan sólo para evitar dicha vergüenza: haber negado que era capaz de enseñar lo justo y lo injusto "hubiese sido, aun cuando sincero y quizá verdadero, social y políticamente desastroso para Gorgias ${ }^{\prime 22}$. Si Gorgias no se hubiese dicho capaz de enseñar lo justo $y$, por el contrario, hubiese repetido lo escrito en su Encomio de Helena, a saber: que la persuasión es una droga capaz de curar o de envenenar ${ }^{23}$, habría tenido que hacerse responsable frente a la multitud de oyentes de estar dispensando un producto potencialmente nocivo para la armonía social de una democracia como la ateniense. Esto último se confirma en el propio diálogo, donde Calicles, discípulo de Gorgias, representa, en su defensa a ultranza de la tiranía, una amenaza concreta para la democracia: "la enseñanza de Gorgias es la semilla de la cual el modo de vida propuesto por Calicles es el fruto venenoso" ${ }^{24}$.

La posición socrática es, respecto del rol de las opiniones del auditorio en la discusión, prácticamente contraria a la del sofista. Si bien en algún momento insinúa la posibilidad de no decir lo que opina por temor a lo que podría pensar Gorgias ${ }^{25}$, lo cierto es que niega de manera rotunda que la opinión de la multitud presente pueda ser relevante:

Yo sé presentar un único testigo de lo que pudiese decir: ese mismo con quien estuviera manteniendo la conversación; no me preocupo por los muchos. Ciertamente, sé someter <la cuestión> al voto de una única persona; no dialogo con multitudes (474a-b).

Y, más adelante: “Muy bien, excelentísimo <Calicles>. Continúa, en efecto, como empezaste, y que no ocurra que te rehúsas por vergüenza (apaischynei). Es necesario, según parece, que tampoco yo me rehúse por vergüenza" (494c) ${ }^{26}$.
En contraposición con Gorgias y Polo, Sócrates insiste en que la única persona relevante al momento de mantener una discusión es aquel con quien se está hablando. La opinión de la multitud - que, en líneas generales, Sócrates suele despreciar en abstracto pero que, en el contexto del Gorgias, está allí presente, escuchando - no debe ser tenida en cuenta al momento de discutir una cuestión ${ }^{27}$.

\section{b) Polo}

Luego de retomar la pregunta por la retórica y de definirla como cierta clase de empeiria, adulación (kolakeia) e "imagen" o "simulacro" (eidolon) de la justicia, Sócrates y Polo abordan la cuestión del poder que los tiranos y los oradores tienen en las ciudades. Como es sabido, Polo considera que la capacidad de cometer toda clase de injusticias en beneficio propio hace del tirano un hombre altamente poderoso y, en consecuencia, feliz. Sócrates rebate esta posición afirmando que, si bien hace lo que le parece mejor para sí mismo, el tirano, no obstante, no hace lo que realmente quiere. El tema deriva, finalmente, en una de las máximas morales de Sócrates por antonomasia: cometer injusticia es peor que padecerla (469b ss.). Para justificar esto, Sócrates apela, como es su costumbre, al lenguaje: en primer lugar, pregunta a Polo si está de acuerdo en que cometer injusticia es más feo / vergonzoso (aischion) que padecerla. Esta apelación a la vergüenza o fealdad moral (aischyne ) que conllevaría la injusticia cometida refiere, necesariamente, a aquella "costumbre de los hombres" de la que hablaba el mismo Polo cuando hacía referencia a las respuestas de Gorgias (482d). La razón por la cual el propio Polo responde afirmativamente a la pregunta socrática termina siendo, pues, similar a aquella por la cual Gorgias se dijo capaz de enseñar lo justo y lo injusto: “¿por qué Polo hace tal concesión? Porque eso es lo que cualquiera respondería (independientemente de lo que realmente piense). La desaprobación moral de la injusticia expresa la opinión pública estándar, de la cual Polo, como buen aprendiz de sofista, es un espejo fiel ${ }^{\prime 28}$. En segundo lugar, Polo acepta que padecer injusticia es peor (kakion) que cometerla. En este caso, la referencia ya no a la vergüenza - que,
22. Kahn (1996, p.65; nuestra trad.). Este modo de proceder parece haber sido habitual, desde el punto de vista platónico, entre los sofistas: "parece que es, Sócrates, como tú dices; al punto que, si realmente para otro es vergonzoso, también lo es para mí decir que la sabiduría y el conocimiento no son, en modo alguno, lo más dominante de todas las cosas humanas" (Prt. 352c-d).

23. “La misma proporción (logos) tiene el poder del discurso en relación con la disposición (taxis) del alma, que la disposición de remedios (pharmaka) en relación con la naturaleza de los cuerpos. Pues tal como, de los remedios, algunos expulsan ciertos humores del cuerpo y otros, otros, y los unos hacen cesar la enfermedad y otros la vida, del mismo modo, de las palabras, unas causan dolor, otras goce, otras temor, otras llevan a quienes escuchan a la temeridad, y otras envenenan (pharmakeuein) y hechizan el alma mediante cierta persuación malvada", Gorgias, Encomio de Helena §14 (DK B 11).

24. Dodds (1959, p.15; nuestra trad.). Cf. Renaud (2001, p.11): "Gorgias no es un enemigo de la moral tradicional como Calicles, en parte quizás porque está demasiado atento a la aprobación pública".

25. “Sócr.- No sea cosa que resulte más grosero decir la verdad. En efecto, temo hablar a causa de Gorgias, no sea cosa que crea que yo me burlo de su ocupación [...] Lo que yo llamo 'retórica' es una parte de cierto asunto que no está entre las cosas bellas.

Gor.- ¿Parte de qué, Sócrates? Habla. No tengas ninguna vergüenza ante mí". (462e-463a).

26. Cf. Apología 22b: “me avergüenza, por cierto, decirles la verdad, señores, pero de todos modos debo decirla".

27. Para el desprecio socrático por las opiniones de los muchos, cf. v.g.Cri.46a ss., Prt. 317a y $R$. 492a ss.

28. Kahn (1996, p.73; destacado original; nuestra trad.). Para la relación entre Polo y la 'opinión pública', cf. 475d, 488e, 489a, 470c-d, 471c, 472a ss. 
según vimos, refiere necesariamente a la mirada de terceros -, sino al mal (kakon) - que se centra en el individuo -, permite a Polo afirmar sin dudas que padecerla es peor que cometerla. Luego de una serie de silogismos que surgen de la negativa de Polo a aceptar que lo bello es lo mismo que lo bueno y, como contrapartida, que lo feo es igual a lo malo, Sócrates termina haciéndole aceptar que cometer injusticia, además de ser más vergonzoso que padecerla, también es peor (474e).

Más allá del análisis pormenorizado que este segmento del diálogo merece ${ }^{29}$, con lo dicho basta para comprender las palabras de Calicles una vez que

29. Para lo cual remitimos a Bieda (2012).

30. Bensen Cain (2008: p.213; trad. y destacado nuestro)

31. Algo similar puede decirse de uno de los argumentos que Critón da a Sócrates para fugarse de la prisión: “de modo que yo siento vergüenza, tanto por ti como por nosotros, tus amigos, de que parezca que todo este asunto tuyo se ha producido por cierta cobardía de nuestra parte" (45d-e). Como se sabe, Sócrates replicará que poco importa la opinión de la mayoría en asuntos como ese, del que nada saben.

32. Kahn (1996: p.74; nuestra trad.)

33. Para un análisis detallado de esta polémica durante las últimas décadas del siglo $\mathrm{V}$ a.C. remitimos a Bieda (2008: §I)

34. Posición similar a las de Trasímaco y Glaucón en R. I-II.
Polo ha sido refutado por Sócrates:

Cal.- Das este discurso público (demegoreis), Sócrates, luego de que Polo haya padecido la misma afección que él mismo acusaba a Gorgias de haber padecido por culpa tuya [...]. Ahora, Polo mismo padeció esa misma afección, por lo cual yo no lo admiro, pues convino contigo que cometer injusticia es más vergonzoso (aischion) que padecerla. En efecto, a causa de este acuerdo, él mismo, aprisionado por ti en los argumentos, fue amordazado, al sentir vergüenza (aischyntheis) de decir lo que pensaba (482c-e).

Una vez más, la mirada de la multitud allí presente ha hecho que Polo, al igual que Gorgias antes que él, aceptara algo en lo que, según Calicles, en realidad no cree: "la vergüenza que impide a Polo expresarse se basa en lo que la mayoría piensa o dice $y$, así, no es más que una convención social; Polo no acepta realmente los valores convencionales de justicia y vergüenza pero, antes que admitir eso en público, se deja atrapar en una dificultad terminológi$\mathrm{ca}^{\prime{ }^{30}}$. Esta "convención social" a la que refiere Bensen Cain no es más que la ya referida "costumbre de los hombres" (ethos ton anthropon, 482d2), costumbre en virtud de la cual se establece el carácter vergonzante o no de un hombre. Tal como ocurriera poco antes con Gorgias, Polo hace prevalecer su reputación pública antes que sus convicciones epistémicas ${ }^{31}$. En palabras de Kahn: “Polo siente vergüenza de negar una verdad moral popularmente reconocida que él mismo, sin embargo, no puede explicar ${ }^{\prime \prime 2}$.

\section{c) Calicles}

La posición de Calicles respecto de la discusión consiste en incluir, como es sabido, una dupla de conceptos característicos del clima de época: la contraposición entre nomos y physis ${ }^{33}$. Lo que Polo ha aceptado, en conformidad con el parecer de los presentes, es que cometer injusticia es más vergonzoso que padecerla desde el punto de vista de las convenciones (nomoi) de los hombres. Por el contrario, la naturaleza (physis) muestra que padecer injusticia es peor y más vergonzoso que cometerla, por cuanto lo que allí impera es la ley del más fuerte (483a ss.). Las leyes convencionales son un invento de los débiles y de la multitud para refrenar el avance natural de los más fuertes ${ }^{34}$. Calicles se anima a decir, pues, lo que ni Gorgias ni Polo antes que él se atrevieron a decir: "si acaso naciera un hombre con la naturaleza adecuada (physin hikanen), tras sacudir, quebrar y rehuir todas estas cosas, tras pisotear, a su vez, nuestros escritos, artificios, encantamientos y absolutamente todas las leyes contrarias a la naturaleza, tras alzarse, el esclavo se revelaría nuestro amo y entonces brillaría lo justo propio de la naturaleza" (483e-484b). Aquel que en un contexto regulado por el nomos es esclavo - i.e. el más fuerte -, en un contexto regulado por la naturaleza se vuelve amo. Dado que las multitudes de hombres son, precisamente, quienes habrían impuesto el imperio de la ley para protegerse de los más fuertes, el hecho de que Calicles pronuncie estas palabras en presencia de muchos de esos débiles da la pauta de que, a diferencia de Gorgias y Polo, está anteponiendo sus convicciones a la mirada de esos otros.

Es esta actitud de Calicles lo que hace que Sócrates se muestre por demás contento ante su tercer interlocutor:

Sóc.- Pienso que quien va a investigar suficientemente acerca del alma, si vive correctamente o no, debe tener, por cierto, tres cosas que tú tienes: conocimiento, buena voluntad y sinceridad de expresión (epistemen te kaì eunoian kaì parresian) [...]. Estos dos extranjeros, Gorgias y Polo, son sabios y amigos míos, pero son más carentes de sinceridad y más vergonzosos de lo que se debe (endeestero parresias kai aischynterotero mallon 
tou deontos). ¿Y cómo no <habrían de serlo>? Han llegado a un punto tal de vergüenza (aischynes) que, por estar avergonzados, cada uno de ellos osa decir cosas contrarias a sí mismo frente a una multitud de hombres (487a-b).

La crudeza de la primera intervención de Calicles, crudeza dirigida tanto a quienes lo precedieron en la conversación como a Sócrates mismo, permite inferir al hijo de la partera que está frente a quien, independientemente de las opiniones que vaya a verter sobre el tema, se halla en la disposición adecuada para la discusión dialéctica: posee un conjunto de convicciones a favor de las cuales puede argumentar - i.e. posee, en un sentido general, episteme -, posee buena voluntad para hacer que la discusión avance $y$, fundamental para nuestros intereses aquí, ejerce sinceramente su libertad de expresión (parresia) ${ }^{35}$. Este ejercicio implica que Calicles pone sus propias convicciones por delante de las opiniones que los demás pudieran formarse de él al escucharlas. A diferencia de Gorgias y Polo, pendientes de la multitud de hombres allí presente, Calicles afirma lo que ellos no se atrevieron a afirmar: "sigues el argumento, Calicles, hablando sinceramente y con nobleza (ouk agennos parresiazomenos), pues ahora dices claramente lo que los demás piensan, pero no quieren decir" (492d). Decir lo que realmente se piensa sobre un asunto implica, pues, tanto el ejercicio pleno y sincero de la libertad de expresión como el hecho de relegar a un segundo plano la vergüenza que las propias opiniones pudieran generar. En este punto, Sócrates y Calicles concuerdan: ambos dicen lo que realmente piensan ${ }^{36}$.

La actitud de Calicles en la discusión con Sócrates es, por lo tanto, sensiblemente distinta a la de Gorgias y Polo pues, si bien, al igual que aquellos, termina aceptando algo en lo que no cree, lo hace explícitamente:

Sóc.- Pero dime ahora: ¿acaso dices que 'placentero' y 'bueno' son lo mismo, o existe alguna entre las cosas placenteras que no es buena?

Cal.- Para que el argumento no se me vuelva contradictorio (anomologoumenos) si acaso dijera que son cosas distintas, digo que son lo mismo (495a) ${ }^{37}$.
Lo que opera en esta respuesta de Calicles no es la vergüenza que podrían generar sus opiniones, sino cierta clase de hartazgo frente a la actitud socrática. Es así que, desde cierto punto de vista, Calicles no comete lo mismo de lo que acusó a quien habló antes que él - cosa que sí le ocurrió a Polo -: en lugar de ratificar su aceptación de conclusiones en las que no cree, opta por dejar de hablar: “Cal.- ¡Qué violento eres, Sócrates! Si acaso me obedecieras, abandonarías esta conversación o bien dialogarías con otro [...]. ¿No podrías recorrer el argumento tú mismo, ya hablándote a ti mismo, ya respondéntote a ti mismo?" (505d). No obstante, esta renuncia a la palabra no debe leerse, a nuestro entender, como un abandono de la parresia, sino como parte de su ejercicio. Si nuestra interpretación previa de la parresia es correcta, lo contrario de la libertad de expresión no es no hablar - cosa que hace Calicles -, sino decir cosas contrarias a las que se cree, por ejemplo, por vergüenza. En este sentido, Calicles opta libremente por suspender el juicio y, así, lleva la libertad de expresión al límite: decidir no hablar forma parte de la libertad de hacerlo. De allí que quede inmune a la crítica que él mismo le hiciera a Polo y éste a Gorgias.

En el presente apartado hemos visto que Gorgias y Polo emiten una opinión acerca del asunto que se discute pero no por ser eso lo que realmente creen, sino por vergüenza a explicitar lo que realmente creen. A primera vista, esta situación parece contradecir ciertos lineamientos básicos del llamado “intelectualismo socrático" (IS), según el cual el único modo de que algo así ocurra es que el agente ignore cuál es su verdadera opinión. El hecho de que ni Gorgias ni Polo intervengan en sendas discusiones posteriores a las propias para desmentir lo que se ha dicho acerca de ellos da la pauta, cuando menos, de que efectivamente ha sido la vergüenza lo que los motivó a aceptar proposiciones con las que no estaban de acuerdo. En lo que sigue intentaremos mostrar de qué modo esto no sólo no contradice el IS, sino que pone en evidencia cuál es su verdadero alcance, de índole más existencial que estrictamente epistemológica.
35. Decimos "ejerce", y no "posee", porque Sócrates ya ha dicho que Atenas goza de una plena licencia para hablar (exousiatoulegein, 461e2). Esta parresía o isegoría era característica de la Atenas democrática: cf. v.g. Demóstenes 9.3; Jenofonte, Ath. 1.12; Eurípides, Hipp. 421 y Ion 670.

36. La principal virtud de Calicles es que su discurso "concuerda consigo mismo": "y que eres capaz de hablar libremente y de no avergonzarte (parresiazesthai kai me aischynesthai), tú mismo lo afirmas y el discurso que poco antes decías concuerda contigo (ho logos ... homologei soi)" (487d). Algo similar dice Sócrates de sí mismo: "yo, por mi parte, creo que es mejor para mí que la lira desafine y desentone, $y$ también el coro que podría dirigir y que muchísimos hombres no estén de acuerdo conmigo sino que digan cosas contrarias, antes que, siendo yo uno solo, sea disonante conmigo mismo y diga cosas contrarias" (482b-c).

37. cf. $501 \mathrm{c}-\mathrm{d}$ 


\section{Elenchos e intelectualismo socrático: la veta existencial}

\section{a) La teoría socrática de la acción: el "intelectualismo socrático"}

El diálogo en el que se exponen de manera más clara los lineamientos de la teoría socrática de la acción es cercano, cronológica y conceptualmente, al Gorgias. En el Protágoras, Sócrates y el sofista discuten acerca de la relación entre valentía y conocimiento:

¿Cómo te hallas, <Protágoras>, en lo que respecta al conocimiento? ¿Acaso también a ti, como a la mayoría de los hombres, te parece esto o <te parece que es $>$ de otro modo? En lo que respecta al conocimiento, a los muchos les parece algo de esta clase: que no es algo ni fuerte ni capaz de guiar ni capaz de gobernar. No piensan, en relación con él, como si fuera algo de tal clase sino que, cuando a menudo el conocimiento está presente en un hombre, <opinan> que no lo gobierna este conocimiento sino algo diferente - algunas veces el impulso-pasional, otras el placer, otras el dolor, a veces el amor y a menudo el miedo -, <y opinan esto > por pensar sin pericia acerca del conocimiento tal como $<10$ harían> acerca de un prisionero-de-guerra, arrastrado en derredor por todas esas cosas. ¿Acaso, por cierto, también a ti te parece que el conocimiento es algo de esta clase? ¿0<te parece> que es algo noble y capaz de gobernar al hombre, y que aunque alguien conociese las cosas buenas y las malas no sería dominado por nada - de modo de hacer ciertas cosas distintas a las que el conocimiento ordenase - sino que la sensatez sería suficiente para auxiliar al hombre? (352b-c).

En pocas líneas Sócrates presenta los postu-

38. Para la distinción entre ética y teoría de la acción socráticas seguimos a GómezLobo (1998: 31); cf. Vigo (2002) y Gulley (1965: 86)

39. Tomamos la fórmula " $(a)$ parece" de Boeri (2007) por entender que recoge el doble sentido ontológico y epistemológico del verbo phainomai. deja de ser un botín de guerra. Sócrates en ningún momento tiene la intención de liberarlo de sus cadenas, sino que pretende que el vencedor en la batalla que se libra por conquistarlo no sean impulsos innobles, sino el bien, la justicia, etcétera; y tales cosas, las virtudes, constituyen, para él, contenidos epistémicos. De allí su afán no tanto por liberar al hombre de todo tipo de sujeción, sino por que dicha sujeción inevitable se corresponda con valores virtuosos.

Que el conocimiento gobierna parece implicar, entonces, que el hombre siempre elegirá en virtud de lo que su estado epistémico le indique como lo más adecuado, dentro del margen de lo posible, en las circunstancias presentes. Ahora bien, ¿significa esto que el hombre siempre elige lo realmente bueno? ¿Significa esto que el error es imposible, dado que siempre se elige el bien? Muy por el contrario, la 'falla' de un hombre condenado a querer lo que su estado epistémico le indica como bueno (en principio para sí mismo) reside en que puede estar siguiendo algo que simplemente le (a) parece bueno (phainomenon agathon) ${ }^{39}$. El problema que detecta Sócrates no es que hay hombres que obran según lo que saben o creen malo para sí mismos, sino que hay hombres que creen que algo es bueno cuando en realidad es malo. El error práctico, según lo dicho hasta aquí, sería estrictamente epistémico, sin connotaciones morales: no hay, en el universo socrático, agentes malos, sino ignorantes. Es por todo esto que Sócrates concluye, en Prt. 352c, que la sensatez (phronesis) es suficiente para auxiliar al hombre. Una vez más: el mal se debe a una falla epistémica y no a una falla vinculada con su querer, esto es: se trata de una falla cognitiva, no volitiva. El querer nunca falla, siempre se dirige hacia lo que se sabe o se considera bueno; la falla puede darse en lo que el agente tiene por "bueno" pero no en sus ansias de realizarlo. Es en este sentido que Vigo afirma que "toda vez que un agente elige algo, y precisamente en la medida en que lo elige, lo elige por considerarlo al mismo tiempo como bueno [...] El fin de una acción, en tanto objeto del deseo que motiva la producción de dicha acción, es intencionado siempre al mismo tiempo como un bien" ${ }^{\prime 40}$. 
Esta breve descripción del $\mathrm{IS}^{41}$ implica que una teoría de la acción como la socrática marcha por una senda distinta - aunque complementaria - a la de su ética. En efecto, una cosa es decir que el querer del hombre siempre apunta al bien y otra es la discusión en torno al contenido material concreto de ese bien. En este sentido, el IS no busca una fórmula para obtener agentes moralmente buenos, sino que se centra en los resortes formales en los que descansan todas las acciones humanas, las buenas y las malas: toda acción tiende a lo que el agente acredita como bueno, en principio para sí mismo. Como decíamos, esto no significa que el agente elija siempre lo realmente bueno, sino que, en términos estrictamente 'descriptivos', muestra que todo hombre actúa con vistas a un bien que es tal en virtud de sus propias consideraciones particulares; a posteriori, dichas consideraciones pueden coincidir, o no, con lo realmente bueno. La única condición que las decisiones del agente deben cumplir es la de la "racionalidad interna": cada nueva decisión debe ser coherente, de facto, con el repertorio de decisiones pasadas y con los deseos y creencias del agente; este requisito de "racionalidad" o "coherencia" interna da cuenta de que esta teoría de la acción no tiene pretensiones estrictamente morales ${ }^{42}$.

La teoría socrática de la acción que estamos comentando no se preocupa, pues, por el contenido material del bien, sino por analizar cómo y por qué el hombre actúa como actúa. Así, en la medida en que se está discutiendo acerca del modo en que se materializa una acción, la diferencia entre lo que es efectivamente bueno y lo que al agente le (a) parece bueno no resulta especialmente relevante: el querer del hombre siempre sigue lo que considera bueno sin preocuparse por el status epistemológico de dicha consideración:

Si, por lo tanto, lo placentero es bueno, entonces nadie, ni cuando sabe ni cuando cree (oute eidos oute oiomenos) que existen otras cosas mejores que las que hace, $y<q u e$ son $>$ posibles $<$ de hacer $>$, hace estas cosas si es posible <hacer> las mejores. $(358 b-c)^{43}$.

"Ni cuando sabe ni cuando cree" significa que nada importa, en términos 'formales', si el agente 'sabe' que la acción $X$ es buena o si simplemente lo 'cree ${ }^{44}$. Si siempre se obra en conformidad con lo que se considera bueno, la condena moral sólo tendrá sentido desde la perspectiva de una tercera persona dado que, desde el punto de vista de la primera persona -que siempre elige un bien para sí mismo -, toda acción es perseguida como buena. En palabras de Gulley, "en el comportamiento moral lo que uno desea alcanzar es invariablemente el bien propio (one's own good), y esta es la meta 'correcta' [...]; la condición de que el agente tenga el deseo de alcanzar la meta 'correcta' es invariablemente satisfecha"; y más adelante: "en el comportamiento moral la concepción de la meta 'correcta' es subjetiva $y$, dado que una persona invariablemente hace lo que cree que está bien relativamente a su concepción de la meta 'correcta', se asume que su habilidad para alcanzar su meta 'correcta' sólo está limitada por la fuerza de circunstancias externas" ${ }^{\prime 45}$. El agente moral no puede sino querer lo que, por el mero hecho de ser querido, es un bien (en principio para él), es la meta "correcta" (en principio para él).

Como ya hemos señalado, el aspecto propiamente moral del pensamiento socrático intenta definir los verdaderos parámetros de lo bueno y lo ventajoso pero no en un plano individual, sino en uno general, intersubjetivo o dialéctico. Esto es, si todos obran en conformidad con lo que a cada uno le parece bueno para sí, la misión socrática será mostrar a esos hombres que tales consideraciones deben ser revisadas $y$, en caso de ser erróneas, modificadas. Una vez más: cuando Sócrates afirma que la acción moralmente negativa nunca es voluntaria y se debe a la ignorancia del bien, no lo hace desde el punto de vista del agente, quien indefectiblemente busca lo mejor para sí. No hay que perder de vista la definición de "ignorancia" en este contexto: “... tener una opinión falsa y engañarse-con-mentiras acerca de asuntos muy valiosos" (Prt. 358c). "Ignorancia" no es lo contrario de lo que podríamos denominar "estado epistémico materialmente determinado" - i.e. ciertos contenidos proposicionales mínimos, sean o no verdaderos, que hacen que ningún agente moral sea una tabula rasa: todos sabemos o creemos saber algo respecto de lo mejor para nosotros mismos -, sino lo contrario a un "estado epistémico proposicionalmente verdadero".
40. Vigo (2002, p. 70)

41. Para una interpretación integral del IS en el Protágoras, cf. Bieda (2011).

42. Para la "racionalidad interna", cf. Vigo (2002) y sus notas. Lo que Sócrates considera imposible es, pues, la "incontinencia", i.e. la irracionalidad interna del agente.

43. En c1 leemos "poiei, kai dunata" (con Schleiermacher y Heindorf).

44. Esta "creencia" es referida mediante un participio del verbo oíesthai, vinculado con el sustantivo "oiesis". Si bien Platón utiliza este sustantivo en contadas ocasiones (Cf. Fedón, 92a7; Crátilo, 420c1; Teeteto, 171a7; Fedro, 244c8; Alcibíades I, 120c6 y 120d6.), su sinonimia con "doxa" es prácticamente indiscutible (cf. LSJ y Bailly s.v. "oiesis").

45. Gulley (1965, pp. 85 y 91-92; nuestratrad). 
Nadie es "ignorante" en el sentido de que no sabe nada; todos, cuando sabemos o cuando creemos, tenemos una determinada idea acerca de lo que nos resultará más ventajoso ${ }^{46}$. De allí que la ignorancia sea entendida, en este contexto, como tener una opinión falsa o engañarse con mentiras. Esto tiene

45. Gulley (1965, pp. 85 y 91-92; nuestratrad).

46. De allí la importancia dada por Sócrates a denunciar que su interlocutor no sabe lo que cree saber: la aporia es condición sine qua non para el conocimiento: "esto es lo penoso de ignorancia: el que alguien que no es noble, ni bueno ni sabio crea tener todo eso en modo suficiente; porque de ninguna manera desea algo de lo que carece quien cree no carecer de ello" (Banquete, 204a; trad. V. Juliá). Cf. Menón, 80a ss. y Apología de Sócrates,

47. En palabras de Gulley: "en el Protágoras no son sólo aquellos que saben lo que está bien quienes actúan voluntariamente. Una acción voluntaria es cualquier acción elegida como un curso de acción posible, ya sea que se sep o bien que se crea bueno" (1965, p. 94 ; nuestra trad.)

48. Cf. Bieda (2012: §III)

49. Cf. Aristóteles, EE 1216b ss: “Sócrates creía que todas las virtudes son conocimientos, de modo que ocurre que conocer la justicia es también, al mismo tiempo, ser justo. En efecto, al mismo tiempo que hemos aprendido la geometría y la construcción somos constructores y geómetras".

50. Dodds (1959: ad460a5) como consecuencia que las acciones que el agente realiza tanto sabiendo como creyendo son voluntarias, dado que lo que nadie haría voluntariamente es elegir un mal a sabiendas ${ }^{47}$. Un acto involuntario sería, por lo tanto, el que se hace en desacuerdo con el objetivo que el deseo del agente hubiese tenido en caso de haber sabido lo que era realmente bueno (al menos para él) y, por lo tanto, lo que hubiese querido hacer verdaderamente.

Sentadas estas bases mínimas del IS, regresemos al contexto del Gorgias para intentar explicar, en este marco teórico, las acciones de Gorgias y Polo.

\section{b) La veta existencial}

El IS socrático está bien atestiguado en el Gorgias $^{48}$. Finalizando la discusión con Gorgias, el propio sofista lo acepta sin más:

Sóc.- El que ha aprendido música, ¿es músico?

Gor.- Sí.

Sóc. - ¿Y quien ha aprendido medicina es médico? ¿Y así con las demás cosas, según el mismo razonamiento: quien ha aprendido cada una es tal como el conocimiento $<$ de ellas $>$ lo vuelve?

Gor.- Ciertamente.

Sóc.- Entonces, según el mismo razonamiento, ¿también el que ha aprendido lo justo es justo?

Gor.- Absolutamente indudable (pántọs dépou).

Sóc. - Y el justo hace cosas justas.

Gor. - Sí. $(460 b-c)^{49}$

Como señala Dodds, esta aceptación por parte de Gorgias no habla tanto de un compromiso con el pensamiento socrático como de su inclusión en ciertas concepciones tradicionales a propósito de la relación entre conocimiento y acción ${ }^{50}$. La novedad de la propuesta socrática, que Gorgias también acepta, reside en la equiparación de la virtud con la esfera de las technai, entre las cuales se halla la retórica, acerca de cuyo status epistemológico se está discutiendo. En este marco, Sócrates hace de la virtud algo equivalente a una técnica, i.e. un cuerpo de proposiciones, cierta clase de 'conocimiento'. La diferencia fundamental, que Gorgias aquí no advierte, es el hecho de que técnicas como la medicina o la música bastan con ser aprendidas para que el agente en cuestión sea considerado "médico" o "músico", mientras que la virtud supone un compromiso ineludible con una acción acorde. En este sentido, un músico que ejecuta mal una pieza, es un mal músico, pero músico al fin. Por el contrario, quien practica mal la justicia, es directamente injusto, no algo así como un 'mal hombre justo'.

Existen ciertas implicancias que la vigencia del IS en el diálogo tiene para el rol de la vergüenza que venimos comentando. En concreto: si ningún hombre obra en contra de sus conocimientos o de las opiniones que tiene por verdaderas, ¿cómo explicar el hecho de que Gorgias haya dado una respuesta que considera falsa a la pregunta socrática por la enseñabilidad de lo justo y Polo, a su vez, haya hecho lo propio a propósito del carácter vergonzoso de cometer injusticia? ¿Se trata de dos contraejemplos del IS, en la medida en que se ha obrado conscientemente en contra de conocimientos u opiniones que se tenían por verdaderas - independientemente de que lo fueran -? Si esto es así, ¿habría que afirmar que, en una situación potencialmente vergonzosa, el IS pierde vigencia en pos de la conservación de la reputación del agente?

En nuestra opinión, no sólo no se trata de dos contraejemplos del IS, sino que estos casos muestran el verdadero alcance de la teoría socrática de la acción que, si bien asociada explícitamente por Sócrates con los contenidos epistémicos del agente, halla su norte definitivo en la traducción práctica de tales contenidos. Esto es, no se trata tanto de qué clase de contenido epistémico se pone en juego - si conocimientos u opiniones verdaderas o falsas -, sino de la integridad moral-existencial del agente al momento de plasmar tales contenidos en la práctica. En este sentido, los conocimientos moralmente relevantes al momento de tomar una decisión concreta no se agotan, ni mucho menos, en las consideraciones materialmente relacionadas 
con la decisión en cuestión, sino que convicciones de otra índole, que involucran la integridad moral del agente ante, por ejemplo, la mirada de terceros, pueden pesar más que tales opiniones. Así, en el caso de Gorgias, si bien es cierto que afirmar que él le enseñará lo justo y lo injusto al discípulo que no lo sepa contradice explícitamente su opinión acerca de la imposibilidad de hacerlo, tal afirmación responde a una proposición existencialmente más relevante que lo lleva a evitar situaciones vergonzosas frente a un auditorio de admiradores y potenciales clientes. Al momento de evaluar riesgos, Gorgias y Polo prefieren ser refutados por un solo hombre (Sócrates) antes que quedar en vergüenza frente aquellos a quienes dicen poder enseñar lo que se les pida: "Polo esconde deliberadamente una posición que sostiene genuinamente; hace, así, lo que cualquier buen orador haría en una situación en la que está siendo públicamente interrogado [...]. Polo es insolente pero precavido: sólo dirá lo que realmente piensa en privado, cuando esté junto a personas que piensen como é e $^{\prime{ }^{51}}$. El bienestar moral, directamente vinculado con la "costumbre de los hombres" (ethos ton anthropon, 482d), se antepone, así, a lo que se tiene por verdadero en el ámbito de la justicia y la injusticia.

Si nuestra interpretación es correcta, se ve que en el IS se pone en juego no tanto el conocimiento u opinión que el agente pudiese tener acerca del tópico involucrado en la decisión por tomar, como el hecho de determinar el mejor curso de acción con vistas al bienestar moral en el marco de una comunidad de hombres. Si yo creo que pagar todos mis impuestos es lo mejor (en principio para mí), pero ninguno de quienes me rodean los paga, el hecho de que yo tampoco lo haga no se explica necesariamente por mi ignorancia acerca del verdadero valor que consituye pagarlos - cosa de la que puedo estar perfectamente seguro -, sino por el hecho de que estoy poniendo la mirada de los otros por encima de mis consideraciones acerca del tópico en cuestión. La salud moral estaría más relacionada, en ese caso, con evitar la vergüenza que me produciría hacer algo que los demás censurarían, aun cuando ello implique contradecir aquello que considero teóricamente o conceptualmente mejor en ese caso puntual. No se trata, como decíamos, de un contraejemplo del IS, cosa que ocurriría en caso de estar decidiendo a sabiendas en contra de mi bienestar, sino de una situación en la cual se da un conflicto práctico - no conceptual - respecto de lo que considero mayor o menor "bienestar" en la situación presente: pagar todos mis impuestos es algo que considero bueno, pero no quedar en vergüenza es algo que se me figura mejor que lo primero. Así, a aquello que Vigo denominaba "racionalidad interna" como requisito para la toma de decisiones, proponemos sumarle lo que podríamos denominar "concordia externa", entendiendo por "concordia" cierta clase de consenso o entendimiento acerca de un asunto, y por "externa" la referencia a terceras personas involucradas en la situación práctica en cuestión.

En este tipo de casos, el elenchos no se compromete tanto con los contenidos epistémicos que se están discutiendo como con la preservación existencial integral del agente: ni Gorgias ni Polo responden lo que consideran verdadero, pero lo hacen con vistas a preservar su integridad moral, aun cuando ello implique la refutación en un plano estrictamente argumental. Esta "veta existencial" del elenchos permite explicar casos en los cuales, IS mediante, el bienestar moral del agente pesa más que la coherencia epistémica. Todo lo que hemos dicho hasta aquí puede resumirse en un parlamento de Polo, poco antes de ser refutado por Sócrates:

Sócr.- ¿Qué es eso, Polo? ¿Te ríes? ¿Es esa otra forma de refutación (eidos elenchou): cuando alguien dice algo, reírse pero sin refutarlo?

Pol.- ¿No crees que quedas refutado (ekelelenchethai), Sócrates, cuando dices cosas tales que ninguno de los hombres diría? Pregunta a alguno de los aquí presentes. $(473 e)^{52}$

El carácter eminentemente político de la filosofía socrática revela su alcance en el hecho de que, incluso en discusiones que parecen plantearse en términos puramente teóricos, la relación con la comunidad de otros hombres, de terceros que asisten a la discusión y se transforman, así, en criterio vivo de lo vergonzoso y lo honroso, es un elemento en algunos casos más relevante aún que el triunfo
51. BensenCain (2008: p.225; nuestra trad.).

52. En Retórica $1419 \mathrm{~b} 3 \mathrm{ss}$. Aristóteles vincula con Gorgias esta forma de refutación que no apela a la argumentación, sino a intentar poner en ridículo al interlocutor. 
en el plano de los conceptos. Para considerar a alguien refutado, a Polo le basta con el hecho de que afirme algo que ningún hombre diría. Si bien el texto del Gorgias no lo dice, es verosímil pensar que Polo consideraría vergonzoso a un hombre tal. Incluso se podría imaginar a alguien que viera cierto peligro en este modo de proceder socrático, peligro que poco a poco iría dando forma a cierta clase de calumnia que acabaría sentando las bases para un juicio:

Ánito.- Sócrates, me parece que con facilidad hablas mal de los hombres. Por mi parte, te aconsejaría, si quieres hacerme caso, que tuvieras cuidado: así como quizás en otra ciudad es más fácil hacerles mal a los hombres que hacerles bien, en esta ciudad es más fácil todavía. Creo que tú mismo también lo sabes (Men. 94e-95a).

En definitiva, si algo muestran las refutaciones de Gorgias y Polo es el hecho de que algunos hombres consideran que lo mejor para ellos mismos no se halla en la salud y coherencia interna de los conocimientos ínsitos en sus almas, sino en la concordia con y la aceptación de los otros.

53. Cf. supra §II.c.

54. Parresia es lo que también parece faltarle a Meleto en la Apología, razón por la cual Sócrates considera su silencio vergonzoso: “¿Ves, Meleto, que callas y no eres capaz de hablar? ¿No te parece, por cierto, algo vergonzoso y prueba suficiente de lo que yo digo?" (24d).

55. En palabras de Renaud: “Gorgias ve refutada su definición de retórica y, de este modo, aprende indirectamente que el divorcio entre la retórica y la justicia es problemático. Su vanidad inicial deja lugar a sentimiento de confusión y, quizá también, al deseo de conocer la verdadera naturaleza de la retórica" (2011, p.12)

56. Cf. R. 346a, Cri. 49c-d y Prt. 331c. Vlastos (1996, pp.32 ss.) analiza esta condición fundamental del elenchos, a

la que denomina "decir lo que realmente se piensa". En contra de la importancia de esta actitud, cf. Beversluis (2000, cap. 2). de Gorgias y de Polo en el Gorgias de Platón, en la medida en que ambos pierden la discusión debido a su afán por evitar la vergüenza que significaría su pérdida del status social que, como maestros de oratoria y de virtud que se precian de ser, tienen ante el público allí presente. Vimos, a su vez, cómo esta posibilidad de sostener voluntariamente y a sabiendas aquello que se considera falso podría chocar, a simple vista, con el IS, pero un análisis más preciso acabó mostrando que lo que el agente busca de manera irrenunciable no es la verdad - esto es, lo que podríamos denominar su "bienestar epistémico" -, sino su bienestar vital o "existencial", lo cual incluye la mirada y opinión de los otros sobre su persona. Visto de este modo, si Gorgias o Polo mienten adrede en sus respuestas, ello no significa que están optando por una vía de acción contraria a sus opiniones acerca de lo mejor, sino que, en la situación presente, lo mejor en términos existenciales no coincide con lo mejor en términos epistémicos (sc. lo que tienen por verdadero). Frente a un conflicto de esta índole, el IS muestra su incumbencia eminente y fundamentalmente práctica, antes que epistémica, al mostrar cómo incluso lo que se tiene por verdadero puede ser dejado de lado con tal de evitar una situación peor a criterio del agente. Las discusiones con Gorgias y con Polo no resultan, así, en una refutación de sus creencias - pues ninguno de ellos dice lo que realmente cree -, sino en un aprendizaje existencial que, mediante sendas denuncias de Polo a Gorgias y de Calicles a Polo, ponen a la sinceridad o autenticidad en el decir (parresia) por encima de la mirada de los otros ${ }^{55}$. De allí la importancia dada por Sócrates a la sinceridad de las respuestas de sus interlocutores: “¡Por la Amistad, Calicles! No creas ni que debes jugar conmigo ni que puedes responder al azar en contra de lo que opinas (para ta dokounta)" (500b) $)^{56}$.

Desbaratar esta especie de escisión entre lo que realmente se piensa y lo que se dice parece ser uno de los objetivos que persiguen los tres elenchoi que atraviesan el diálogo. En efecto, el mito final muestra precisamente que, incluso cuando alguien haya vivido una vida decorosa en el plano visible de sus acciones, será castigado tras la muerte del cuerpo en caso de albergar injusticia en el alma ${ }^{57}$. De 
esto se infiere, pues, que mentir con vistas a evitar la vergüenza de decir algo políticamente incorrecto es, para Sócrates, peor que ser refutado. En definitiva, la misión socrática en Atenas no fue más que un intento no tanto de purgar epistémica o intelectualmente a sus conciudadanos, sino de que dicha purga se tradujera en acciones que dieran lugar a una pólis justa y feliz. Esta combinación inescindible entre el saber y la vida, entre lo epistémico y lo existencial, se halla presente en la que probablemente sea la máxima moral socrática por antonomasia: "la vida sin investigación no es digna de ser vivida para un hombre" (Apología 38a).

Por el contrario, al poner la vergüenza por encima de lo que se considera verdadero, Gorgias y Polo se revelan representantes de lo que Dodds y otros antes que él denominaron "cultura de la vergüenza", que, si bien usualmente adscripta al hombre homérico, no deja de tener representantes concretos en el período clásico $^{58}$. En este tipo de culturas, "el sumo bien del hombre [...] no es disfrutar de una conciencia tranquila, sino disfrutar de timé, de estimación pública [...]. En tal sociedad, todo lo que expone a un hombre al desprecio o a la burla de sus semejantes, todo lo que lo hace 'quedar corrido', se siente como insoportable ${ }^{\prime{ }^{59}}$. Tal como a Aquiles, deudor de aquella aischyne homérica que comentamos al comienzo de nuestro trabajo, no le interesa hacer lo 'correcto' - i.e. luchar junto al ejército aqueo -, sino obtener la honra de los soldados, a Gorgias y a Polo, representantes de cierta línea sofística de la retórica, no les interesa llegar a la verdad, sino obtener un triunfo que les reporte reconocimiento público 0 , en caso de ser esto imposible, evitar la vergüenza. A esta tendencia arcaizante de sus dos primeros interlocutores, Sócrates contrapone la escala de valores de una filosofía que pone a la verdad y a la sinceridad como únicos resortes posibles de la dignidad y el honor, pero de una dignidad que no se establece en virtud de la mirada de una sociedad moralmente defectuosa como la ateniense, sino, más que nada, frente a uno mismo.

\section{Bibliografía}

ARCHIE, J.P. (1984). Callicles' Redoubtable Critique of the Polus Argument in Plato's Gorgias". Hermes CXII, 2, pp. 167-176.

BENSEN CAIN, R. (2008). Shame and ambiguity in Plato's Gorgias. Philosophy and Rhetoric XLI, 3, pp. 212-237.

BENSON, H. (1987). "The Problem of the Elenchus Reconsidered", en PRIOR, W. J. (ed.) (1996), pp. 97-118

BENSON, H. (1995). The Dissolution of the Problem of the Elenchus. Oxford Studies in Ancient Philosophy XIII, 45-112.

BEVERSLUIS, J. (2000). Cross-examining Socrates. A Defense of the Interlocutors in Plato's Early Dialogues, CUP.

BIEDA, E. y MÁRSIC0, C.T. -eds.- (2013). Expresar la phýsis. Conceptualizaciones antiguas sobre la naturaleza. Buenos Aires, EdUNSAM.

BIEDA, E. (2012). Boceto de una desintegración psíquica en el Gorgias de Platón. Hypnos XXIX, Editora da PUC-SP, San Pablo, pp. 237-257.

BIEDA, E. (2011). Creer o saber, esa no es la cuestión. Opinión y conocimiento en el Protágoras de Platón. Circe de clásicos y modernos vol. XV, Miño y Dávila, Santa Rosa, pp. 27-40 (a doble columna por página).

Antifonte Sofista. Un utilitarismo naturalista. Méthexis. International Journal of Ancient Philosophy XXI, pp. 23-42.

BRICKHOUSE, T.C. \& SMITH, N.D. (1996). “Socrates' Elenctic Mission", en PRIOR -ed.- (1996), pp. 119-144.

CONSENTINO, M. (2013), “El élenkhos en Laques”, en BIEDA, E. y MÁRSIC0, C. (2013).

DODDS, E.R. (1959), Plato. Gorgias, 0xford, Clarendon Press.

DODDS, E.R. (1997), Los griegos y lo irracional, Madrid, Alianza (versión castellana de The Greeks and the Irrational, The University of California Press, 1957).

FUTTER, D.B. (2009). Shame as a Tool for Persuasion in Plato's Gorgias. Journal of the history of philosophy XLVII, 3, pp.451-461.

GRUBE, G.M.A. (1984). El pensamiento de Platón, Madrid, Gredos (versión castellanda de Plato's Thought. Methuen \& Co. Ltd., 1970).

GULLEY, N. (1965). The interpretation of 'No one does wrong willingly' in Plato's dialogues". Phronesis $\mathrm{X}, 1$.

GUTHRIE, W.K.C. (1998). Historia de la filosofía griega IV. Platón, el hombre y sus diálogos: primera época, Madrid, Gredos (versión castellana de A History of Greek Philosophy. Volume IV, CUP, 1962).

INVERSO, H. "Élenchos y tipos discursivos en Banquete y Eutidemo", en BIEDA, E. y MÁRSICO, C.T. (2013).

IRWIN, T. (1979). Plato. Gorgias, Oxford, Clarendon Press.

KAHN, Ch (1996). "Drama and dialectic in Plato's Gorgias", en PRIOR (1996), pp. 60-96. 
MOSS, J. (2005). Shame, Pleasure, and the Divided Soul. Oxford Studies in Ancient Philosophy XXIX, pp. 137-170.

PRIOR, W.J. -ed.- (1996). Socrates. Critical Assessments. Londres, Routledge.

RACE, W.H. (1979). Shame in Plato's Gorgias. The Classical Journal LXXIV, 3, pp. 197-202.

RENAUD, F. (2001). La rhétorique socratico-platonicienne dans le Gorgias (447a-461b). Philosophie Antique 1, 2001, pp. 65-86 (versión castellana de Bárbara Steinman).

ROBINSON, R. (1996). “Elenchus", en PRIORI (1996), pp. 9-19.
VIG0, A. (2002). Autodistanciamiento y progreso moral. Reflexiones a partir de un motivo de la ética socrática. Diadokhé V, 1-2, pp. 65-101.

VLASTOS, G. (1994). Socratic Studies, CUP.

VLASTOS, G. (1996). "The Socratic Elenchus", en PRIOR (1996), pp. 28-55.

Recebido em fevereiro de 2014, aprovado em outubro de 2014. 